\title{
Ciberbullying en colegios privados y estatales de primaria en dos distritos de Lima Metropolitana
}

\author{
Isabel Amemiya, Miguel Oliveros, Yolanda Condorimay, Armando Barrientos, Bruno Rivas
}

DA Medicina Preventiva y Salud Pública e Instituto de Ética, Facultad de Medicina, UNMSM

Objetivos: Determinar las caracteristicas del ciberbullying en escolares 5 to y 6 to de primaria de colegios estatales y particulares, de Jesús Maria y Pueblo Libre.

Diseño: Descriptivo transversal.

Institución: DA Medicina Preventiva y Salud Publica e Instituto de Ética, Facultad de Medicina, UNMSM.

Participantes: Alumnos de 5 to y 6 to de primaria.

Intervenciones: En 826 alumnos de 5to y 6to de primaria, de colegios estatales y particulares, de Jesús María y Pueblo Libre, se aplicó la encuesta anónima de Rosario Ortega. Se realizó análisis descriptivo y pruebas estadísticas de asociación.

Principales medidas de resultado: Características del ciberbullying en escolares.

Resultados: Se comunicó ciberbullying en $24,7 \%$, fue mayor en 6 to grado y en colegios privados. La agresión por celular e internet ocurrió en $1,9 \%$, víctimas por celular en $6,3 \%$ y por internet $12 \%$. Ser víctima por internet se asoció a presencia de computadora en el cuarto $(p=0,019)$ y al uso de internet fuera de casa $(p=0,000)$; fue mayor en colegios privados $(p=0,002)$ y cuando se empleó internet fuera de casa aumentó a $23,1 \%(p=0,032)$. Los varones agredieron más que las mujeres $(p=0,000)$.

Conclusiones: El ciberbullying fue más frecuente en alumnos de 6to de primaria de colegios privados. Las víctimas por internet fueron más frecuentes que por celular, y se asociaron a tener computadora en su cuarto o usarlos fuera de casa. Predominó la agresión en los varones.

Palabras clave: Intimidación, adolescente, estudiantes, violencia, agresión, acecho, Perú (DeCS BIREME), ciberbullying.

\section{Estudio de la satisfacción del usuario de la unidad de bienestar universitario de la Facultad de Medicina, UNMSM}

Justina Najarro, Miriam Palomino, Christian Palomino, Julio Vázquez, Aníbal Pacheco, Gloria Cerna, Sabino Garcés

Facultad de Medicina, UNMSM

Objetivos: Analizar la satisfacción de los servicios brindados por la Facultad de Medicina, del área de Psicología, Consultoría Social, nutricional y médico.

Diseño: Descriptivo

Institución: Facultad de Medicina, UNMSM.

Participantes: Estudiantes.

Intervenciones: Se realizó encuesta a 500 estudiantes.

Principales medidas de resultados: Porcentajes de satisfacción.

Resultados: De los 500 alumnos encuestados, 113 visitaron algún consultorio de bienestar. Sobre el horario de atención, a $57 \%$ de los estudiantes le gustaría asistir al consultorio en la tarde; $62 \%$ opinó que el tiempo de espera para la atención era lento, $48 \%$ señaló que siempre la vestimenta era adecuada; $32 \%$ dijo que siempre el personal lo escuchaba y atendía sus inquietudes. El $72 \%$ indicó que a veces las recomendaciones del personal solucionaron su problema, $58 \%$ (66) que la infraestructura del consultorio es regular, $48 \%$ que la limpieza y orden del ambiente fue regular, $45 \%$ que la higiene del servicio era buena, $44 \%$ que era regular, $74 \%$ que a veces mantiene su privacidad.

Conclusiones: Pocos alumnos conocen el servicio de bienestar universitario que brinda la Facultad y los servicios no cubrieron sus expectativas.

Palabras claves: Satisfacción de usuario, calidad de los servicios. 